\title{
The Psycho-Grammatical Description of the Existential Locative "there" Constructions
}

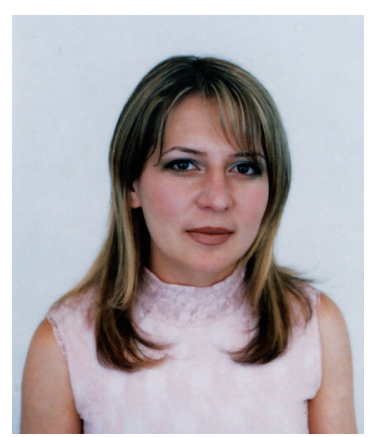

Armine Suvaryan
$\mathrm{T}$

The focus of the present paper is the psychogrammatical description of the existential locative "there" constructions in English. Nowadays, various functional and semantic realizations of these constructions are discussed in great deal, but less attention is ever paid to its psycho-grammatical description.

Psycho-linguistics is a relatively new science and the continued interest in it proves the fact of its being in the mainstream of linguistic thought and research. It attempts at explaining the unseen mental processes that go inside the organism and the language.

As the French linguist Guillaume established as early as 1919 in a challenging theory called psycho-systemics and as N.Chomsky later contended in Aspects of the Theory of Syntax(1965) sentences are surface structures that originate in the depths of the speaker's mind. Chomsky compared the sentences to the finished product coming out on a conveyer belt after an extremely short but complex manufacturing process involving the speaker's mental capacities.

Traditional grammar studied the sentence from the point of view of its syntagmatic structure: the sentence was approached as a string of certain parts fulfilling the corresponding syntactic functions. Grammar is the support system of communication and we learn it to communicate better. But when we use grammar structures in conversations, composition or letters, we unconsciously perform various operations* like predication, compounding etc, being quite unaware of the innumerable mental operations involved in them.

Such mental operations reflect not only the speaker's linguistic competence but also the way in which the mind functions in a given environment, they are part of their grammatical subconsciousness and may be called psycho-grammatical in so far as they imply workings of the mind (psycho-) aimed at generating linguistic structures (-grammatical) (Lapaire; Rotge, 1997). To the naked eye these psycho-grammatical operations are abstract and invisible but they may leave concrete 'marks' in discourse. A good illustration of this is provided by the existential locative "there" constructions, where we treat grammatical morphemes th- and -ere not only as mere 'forms' but as markers that signal the workings of the mind.

Historical linguistics defines $t h$ - as a 'demonstrative stem', which suggests that, not so long ago, th- possessed specific grammatical features and was not a meaningless form 
at all. What $t h$ - has retained of its demonstrative origin is the existence of earlier mental operations, which depend on the one hand on the given moment in time and given place, on the other hand on the morpheme that th- combines with, for example -ERE in THERE.

French linguists are of the same opinion, they tend to think that existential constructions with "there" involve the prior mental activity th- of situational knowledge -ere by the speaker, which is true both for 'abstract' and 'concrete' realizations of "there".

The analysis has shown that the "concrete' realization of "there" is typical of spoken English, for stance, we come across such uses of "there" in spontaneous conversations, when it is used to attract somebody's attention to a particular place, thing or fact. It should be mentioned that attracting somebody's attention is not a simple thing.

Attention is the process of focusing perception on a single stimulus or a limited range of stimuli. We must first use our sense organs, collect information and only then we make gesture. For example,
1. You there! Come back!
2. The cash desk is over there.
3. There come the others.
4. There goes my last pound note.
5. There goes the last bus.(we have just missed it).

In the first two sentences "there" presupposes that 'something' has gone before', since you cannot say You there! Come back! If you have not established your own position as being here. Th- signals prior mental activity.

In the sentences (3), (4), (5) 'th- ' signals that the speaker thinks that the information is known to the addressee. That is to say I am sure that you as well heard their approaching footsteps in There come the others, the noise of passing bus and the last pound note in There goes the last pound note.

In the above mentioned sentences - ere signals either direct location or refers more loosely to the situation.

These psycho-grammatical features are active not only in stress pattern and syntactic arrangement. The 'abstract' realization of "there" is typical of existential sentences. Besides we come across a great number of these constructions in idioms, when we are not interested in the referential meaning of morphemes. For example,

1. To be sure there was always the next station where one might descend and return.

2. There was the great city, bound more closely by these very trains which came up daily.

3. There is a good boy/girl. (said to a child in praise for having done something well). 
4. There! There! There now! ( said in a sympathetic tone to comfort or calm someone).

5. There is gratitude/thanks for you! (this may be said sincerely or ironically, depending on the situation)

6. There he/she goes again! (this is meant as a sarcastic comment when someone repeatedly speaks about or does the same thing)

7. ... and there you are! (this is added to an instruction of how to do something; e.g. Put the plug in, turn the knob to 'On', press the button for 'Start' and there you are!)

8. There goes my career!(humorous).

All the above mentioned existential sentences and idioms are tied to a given situation (-ere), earlier observation, and experience(th-). Focusing more on psychogrammatical phenomena we understand that it is a means which builds up a 'mental space' in which the speaker and the addressee are both present at a given moment in time and at given place.

Thus, in contemporary modern linguistics the psycho-grammatical description of the language opens up a new stage in the development of the science of language, it is not the psycho-grammatical approach that has provided a comprehensive theoretical ground for treating the sentence not only as a ready made unit of speech, but also as the way in which the mind functions in a given environment.

The present analyses comes to prove once again that cognitive and mental processes should become essential components of simple explanatory procedures, even if "the neurological mysteries of "black box", where words mate and sentences sprig to life - remain to be solved" (Lapaire; Rotge, 1997).

\section{Notes:}

* Operation is derived from the Latin verb operari, which means 'to work'.

\section{References:}

1. Chomsky, N. (1965) Aspects of the theory of syntax. Cambridge. MA: MIT Press.

2. Lapaire, Jean-Remi; Rotge, Wilfred (1997) Functional Approaches to Written Text. Washington, D.C.: US Information agency.

3. Seidl, J.; McMordie W. (1983) English Idioms and How to Use Them. Moscow: Vyshaya Shkola. 


\section{“There” qnjnıptGulquG-untinh vimlpujny lunnıjgh hnqtipuGulquG- ptpulquaulua panıpuqhnn}

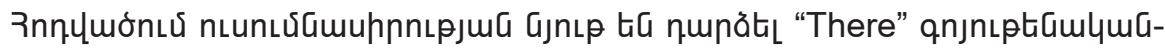

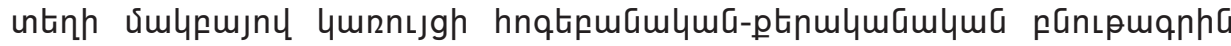
unąunn fuGinhnatip:

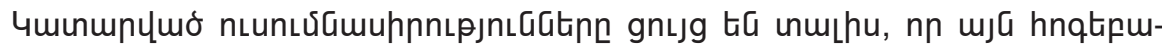

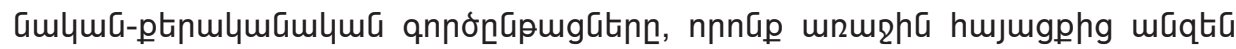

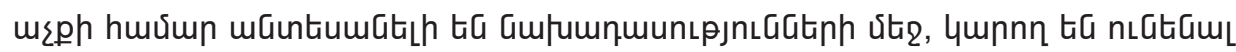
nntiGg unGulntiun nnulunnnเưGinn fununt.jpnเú: 